\title{
Optimal Taxation and Redistribution in an OLG Model with Unemployment*
}

\author{
Thomas Aronsson, Torbjörn Dalin and Tomas Sjögren \\ Department of Economics, Umea University, \\ SE - 90187 Umea, Sweden
}

March 2004

\begin{abstract}
This paper concerns redistribution and optimal taxation in an OLG model with two employed ability-types. We assume that the wage rates are determined by bargaining between unions and firms, implying that the equilibrium is characterized by unemployment. The tax instruments are nonlinear taxes on labor income and capital income. We show that the policy instruments that are used to calculate the marginal labor income tax rate for each ability-type give rise to intertemporal tax base effects. As such, dynamic models may provide insights with respect to labor income taxation, which are not easily gained in static models. In addition, since the relationship between the employment and the capital stock implies production inefficiency at the second best optimum, imperfect competition in the labor market may, itself, justify capital income taxation.
\end{abstract}

Keywords: Optimal taxation, OLG model, union wage setting

JEL Classification: H21, H23, J51

${ }^{*}$ A research grant from FAS is greatfully acknowledged. 


\section{Introduction}

Several studies on optimal taxation have addressed the implications of excess supply of labor. Part of the earlier literature has concentrated on proportional tax instruments ${ }^{1}$. In this paper, we consider optimal nonlinear taxation $^{2}$ of labor income and capital income, and the analysis is carried out in the context of an overlapping-generations (OLG) model, where both the private agents and the government solve intertemporal optimization problems. The paper relates to (and tries to combine) earlier literature in two fields; (i) optimal nonlinear taxation and redistribution under unemployment and (ii) optimal nonlinear taxation and redistribution in dynamic models. In the first of these two research areas, previous studies typically use static models, meaning that they disregard capital taxation, whereas previous studies in the second area are based on the assumption of competitive labor markets.

To our knowledge, Marceau and Boadway (1994) is the first paper to address involuntary unemployment in the context of redistribution via nonlinear income taxation. Their study is based on an extension of the two-type model developed by Stern (1982) and Stiglitz (1982), and the analysis carried out in the paper focuses on the welfare effects of minimum wages and unemployment insurance. Similarly, Aronsson and Sjögren (2003) consider redistribution and provision of public goods under union wage setting in the context of a mixed tax problem for an economy with two ability-types. Their main contribution is to show how employment-related motives behind policy may modify the use of income taxation, commodity taxation and public

\footnotetext{
${ }^{1}$ See e.g. Andersen et al. (1996), Bovenberg and van der Ploeg (1996), Boeters and Schneider (1999) and Koskela and Schöb (2002).

${ }^{2}$ Seminal contributions to the nonlinear and mixed tax problems in the context of static models with competitive markets are Mirrlees (1971), Atkinson and Stiglitz (1976), Mirrlees (1976), Atkinson (1977), Stiglitz (1982) and Edwards et al. (1994).
} 
good provision. Another part of the literature focuses more explicitly on labor income tax progression in economies with unemployment; by relating the optimal degree of progression to, among other things, the structure of wage bargaining and/or the incentives underlying the choice of work hours ${ }^{3}$.

Earlier studies on optimal taxation and redistribution in dynamic models include e.g. Ordover and Phelps (1979), Brett (1997), Boadway et al. (2000) and Pirttilä and Tuomala (2001) $)^{4}$. Ordover and Phelps (1979) use a model with a continuum of ability-types and show that, if private consumption and leisure are separable in terms of the utility function, then the marginal capital income tax rate should be zero for each ability-type. Brett (1997) considers an OLG framework with two ability-types. He finds that the marginal capital income (or savings) tax rate of the low-ability type can be either positive or negative at the second best optimum, depending on the difference in relative valuation of present and future consumption between the low-ability type and a mimicking high-ability type, whereas the marginal capital income tax rate of the high-ability type is zero. Pirttilä and Tuomala (2001) further develop the analysis of Brett by thoroughly addressing endogenous wage rates. Their results show - in addition to the mechanism discussed by Brett - that production inefficiency at the second best optimum justifies capital income taxation. Finally, Boadway et al. (1998) analyze nonlinear labor income taxation and proportional capital income taxation in a model where both ability and initial wealth are unobserved by the gov-

\footnotetext{
${ }^{3}$ See e.g. Fuest and Huber (1997) and Aronsson and Sjögren (2004a). See also Aronsson and Sjögren (2004b); in their study, firms have the option to move production abroad in case the wage negotiations break down, implying that the tax and expenditure policies abroad will affect the domestic wage structure and vice versa.

${ }^{4}$ See also Chamley $(1985,1986)$, who consider optimal taxation in a representative agent model of Ramsey growth type, where agents have infinite time horizons. The main issues in these studies refer to efficiency aspects of taxation.
} 
ernment. In their framework, the capital income tax is interpretable as an indirect instrument to tax wealth.

Our study is based on the assumption that both labor income and capital income are taxed according to nonlinear schedules. We consider a two-type framework with a general (nonseparable) utility function and endogenous before tax wage rates. Except for the description of the labor market, this means that the model resembles that used by Pirttilä and Tuomala (2001). We assume that unions and firms bargain over the wage rates in the context of the right-to-manage framework, meaning that the equilibrium is characterized by unemployment. The paper contributes to the literature in two ways. First, it allows us to characterize the use of labor income taxation in an economy with intertemporal optimization and imperfect competition in the labor market. Second, we are also able to characterize the optimal marginal capital income tax rates under unemployment. To our knowledge, neither of these two issues have been addressed in previous studies. Our results show that the policy instruments used to calculate the optimal marginal labor income tax rate for each ability-type give rise to intertemporal tax base effects, indicating that the use of dynamic models is important for understanding the structure of labor income taxation. We also show that the relationship between the employment and the capital stock implies production inefficiency at the second best optimum, which provides additional motives for using capital income taxation.

The outline of the paper is as follows. Section 2 concerns the optimization problems of consumers, firms and unions. We also characterize the outcome of private optimization. In section 3, we analyze the optimal tax policy. Section 4 summarizes the paper. 


\section{The Model}

\subsection{Consumers and Firms}

Consider an overlapping generations economy, where each generation lives for two periods. There are two types of consumers participating in the labor force; a low-ability type (denoted by superindex 1 if employed) and a highability type (denoted by superindex 2 if employed). This distinction between ability-types refers to productivity, implying that the high-ability type faces a higher before tax wage rate than the low-ability type. We assume that the number of consumers of each ability-type, $m^{i}$ for $i=1,2$, is constant, and denote the number of employed persons of ability-type $i$ at time $t$ by $n_{t}^{i}$.

The consumers share a common utility function. We also make the conventional assumption that consumers only work during the first period of life (if employed). The utility function of an individual of type $i$ born in period $t$ is written $U_{t}^{i}=U\left(c_{t}^{i}, z_{t}^{i}, x_{t+1}^{i}\right)$, where $c_{t}^{i}$ is consumption during the first period of life, $x_{t+1}^{i}$ consumption during the second period and $z_{t}^{i}$ leisure ${ }^{5}$. Leisure is, in turn, defined as $z_{t}^{i}=H-l_{t}^{i}$, where $H$ is a time endowment and $l_{t}^{i}$ the hours of work. The function $U(\cdot)$ is increasing in each argument and strictly quasiconcave, and we assume that all goods are normal.

If employed, the budget constraint is written

$$
\begin{aligned}
w_{t}^{i} l_{t}^{i}-T\left(w_{t}^{i} l_{t}^{i}\right)-s_{t}^{i} & =c_{t}^{i} \\
\left(1+r_{t+1}\right) s_{t}^{i}-\Phi\left(r_{t+1} s_{t}^{i}\right) & =x_{t+1}^{i}
\end{aligned}
$$

where $w_{t}^{i}$ is the wage rate facing type $i$ in period $t, s_{t}^{i}$ savings and $r_{t+1}$ the interest rate, while the consumer prices are normalized to one for notational convenience. The functions $T(\cdot)$ and $\Phi(\cdot)$ represent the payments of labor

\footnotetext{
${ }^{5}$ The leisure argument refers to the first period, when the individual is part of the labor force. The utility of leisure in the second period is suppressed.
} 
income taxes and capital income taxes, respectively. In the analysis to be carried out below, we will use the following short notations

$$
\begin{aligned}
T_{t}^{i} & =T\left(y_{t}^{i}\right), & \Phi_{t+1}^{i}=\Phi\left(I_{t+1}^{i}\right) \\
T_{t, y}^{i} & =\frac{\partial T\left(y_{t}^{i}\right)}{\partial y_{t}^{i}}, & \Phi_{t+1, I}^{i}=\frac{\partial \Phi\left(I_{t+1}^{i}\right)}{\partial I_{t+1}^{i}}
\end{aligned}
$$

where $y_{t}^{i}=w_{t}^{i} l_{t}^{i}$ and $I_{t+1}^{i}=r_{t+1} s_{t}^{i}$. By using the first order conditions, we can write the marginal labor and capital income tax rates as follows;

$$
\begin{aligned}
T_{t, y}^{i} & =1-\frac{1}{w_{t}^{i}} \frac{U_{t, z}^{i}}{U_{t, c}^{i}} \\
\Phi_{t+1, I}^{i} & =1+\frac{1}{r_{t+1}}\left(1-\frac{U_{t, c}^{i}}{U_{t, x}^{i}}\right)
\end{aligned}
$$

where $U_{t, c}^{i}=\partial U_{t}^{i} / \partial c_{t}^{i}, U_{t, z}^{i}=\partial U_{t}^{i} / \partial z_{t}^{i}$ and $U_{t, x}^{i}=\partial U_{t}^{i} / \partial x_{t+1}^{i}$. Conditional on the tax system, equations (3) and (4) define the hours of work and savings as functions of the wage rate and the interest rate, i.e. $l_{t}^{i}=l\left(w_{t}^{i}, r_{t+1}\right)$ and $s_{t}^{i}=s\left(w_{t}^{i}, r_{t+1}\right)$.

If the consumer is unemployed, on the other hand, he/she will receive tax-free benefit (which is independent of ability), $b_{t}$. The intertemporal budget constraint can be written

$$
\begin{aligned}
b_{t}-s_{t}^{u} & =c_{t}^{u} \\
\left(1+r_{t+1}\right) s_{t}^{u}-\Phi\left(I_{t+1}^{u}\right) & =x_{t+1}^{u}
\end{aligned}
$$

in which the superindex " $u$ " refers to 'unemployed' and $I_{t+1}^{u}=r_{t+1} s_{t}^{u}$. By using the first order conditions, we obtain

$$
\Phi_{t+1, I}^{u}=1+\frac{1}{r_{t+1}}\left(1-\frac{U_{t, c}^{u}}{U_{t, x}^{u}}\right)
$$


where $\Phi_{t+1, I}^{u}=\partial \Phi\left(I_{t+1}^{u}\right) / \partial I_{t+1}^{u}$, while the utility of an unemployed individual becomes $U_{t}^{u}=U\left(c_{t}^{u}, H, x_{t+1}^{u}\right)$. Equation (7) can be used to derive a savings function; $s_{t}^{u}=s\left(b_{t}, r_{t+1}\right)$. Since individuals have identical preferences, equations (5)-(7) apply to unemployed individuals of both ability-types.

Following some previous studies, such as Fuest and Huber (1997) and Aronsson and Sjögren (2004a, 2004b), we also introduce a second category of consumers: firm-owners ${ }^{6}$. The reason is that the production technology is characterized by decreasing returns to scale (see below), which simplifies the description of the labor market part of the model ${ }^{7}$. We also follow previous studies by assuming that the firm-owners do not participate in the labor market, implying that their only source of income is the profits. Since the number of firm-owners is fixed, it will be normalized to one for each generation. In addition, as we are considering an intertemporal model, it is necessary to specify the timing of income for the firm-owner. Without loss of generality, and by analogy to the timing of income for the other agent-types in the model, we assume that the fixed production factors, in each period, are transferred to the young generation of firm-owners, implying that the budget constraint of the firm-owner can be written

$$
\begin{aligned}
\pi_{t}\left(1-\kappa_{t}\right)-s_{t}^{p} & =c_{t}^{p} \\
s_{t}^{p}\left(1+r_{t+1}\right)-\Phi\left(r_{t+1} s_{t}^{p}\right) & =x_{t+1}^{p}
\end{aligned}
$$

where the superindex " $p$ " refers to 'firm-owner', whereas $\pi_{t}$ is profit income

\footnotetext{
${ }^{6}$ The firm-owners are interpretable as the owners of any fixed production factor, e.g. land, vital aspects of production techniques, etc.

${ }^{7}$ Instead of introducing the firm-owners, other alternatives would be to assume that the profit income is equally distributed among workers or introduce a stock market. Given the analysis to be carried out below, it does not matter much for the results which option is chosen. Introducing the firm-owners is slightly more convenient than the other alternatives from a computational point of view.
} 
and $\kappa_{t}$ the profit income tax in period $t$. The first order conditions can be written in a way similar to equation (7), and the utility of the firm-owner becomes $U_{t}^{p}=U\left(c_{t}^{p}, H, x_{t+1}^{p}\right)$.

Turning to the production side, we assume that identical competitive firms produce a homogenous good, and we abstract from possible entry into, and exit out of, the goods market. Given these characteristics, the number of firms is not important and will be normalized to one. In each period, $t$, the firm uses three variable production factors; labor of both ability-types, $L_{t}^{1}$ and $L_{t}^{2}$, and capital, $K_{t}$. The labor input of each abilitytype, $i$, measures the total number of work hours and is defined as the number of employed persons, $n_{t}^{i}$, times the hours of work per employee, $l_{t}^{i}$. The production function is written $F\left(L_{t}^{1}, L_{t}^{2}, K_{t}\right)$, which is increasing in each argument. We also assume that the production is characterized by decreasing returns to scale. In each period, the firm behaves as if it maximizes profits net of taxes

$$
\pi_{t}=\left[F\left(L_{t}^{1}, L_{t}^{2}, K_{t}\right)-w_{t}^{1} L_{t}^{1}-w_{t}^{2} L_{t}^{2}-r_{t} K_{t}\right]\left(1-\kappa_{t}\right)
$$

The first order conditions for profit maximization are $F_{L^{i}}\left(L_{t}^{1}, L_{t}^{2}, K_{t}\right)-w_{t}^{i}=$ 0 for $i=1,2$ and $F_{K}\left(L_{t}^{1}, L_{t}^{2}, K_{t}\right)-r_{t}=0$, where the subindices denote partial derivatives. The first order conditions implicitly define the labor demand functions $L_{t}^{i}=L^{i}\left(w_{t}^{1}, w_{t}^{2}, r_{t}\right)$ for $i=1,2$, which satisfy $\partial L_{t}^{i} / \partial w_{t}^{i}<0$.

\subsection{The Labor Market}

Let us now turn to the labor market and characterize wage formation. Each ability-type is organized by ability-type specific trade unions. We assume that wage formation is decentralized in the sense that the unions treat the decision variables of the government and the interest rate as exogenous. Given these characteristics, the number of unions is not important. As 
a consequence, and by analogy to the treatment of the production sector above, we normalize the number of unions for each ability-type to one.

There are several possible approaches to describe the objective function of a union ${ }^{8}$, and there seems to be no consensus regarding the most appropriate formulation. Following Oswald (1993), we consider a model, where there is a known lay-off ordering. The basic motivation is that unemployment is typically governed by seniority rules (e.g. 'last in, first out') and not by random draw. As a consequence, if the majority of the union members are not at an immediate risk of becoming unemployed, the union will be locally indifferent to the level of employment. To be more specific, we assume that the employment opportunities are allocated among union members according to exogenous seniority $\operatorname{rules}^{9}$, and that the majority of union members are employed. Except that the employed union members differ with respect to seniority, they are identical and receive the same wage rate. In this case, it is natural to assume that the objective of union $i$ in period $t$ coincides with the objective function facing the majority of its members; $U_{t}^{i}=U\left(c_{t}^{i}, z_{t}^{i}, x_{t+1}^{i}\right)$.

The wage rate is determined by bargaining between the union and the firm within the right-to-manage framework. Each union bargains separately with the firm, and it behaves as a Nash competitor towards the firm as well as towards the other union. If no contract is signed, the union members become unemployed and obtain the fall-back utility, $U_{t}^{u}$, whereas the fallback profit of the firm is zero. By defining the rent from bargaining for union $i$ as $\Lambda_{t}^{i}=U_{t}^{i}-U_{t}^{u}$, the outcome of the bargain for ability-type $i$ will be the wage rate that maximizes

$$
\Omega_{t}^{i}=\left[\Lambda_{t}^{i}\right]^{\alpha^{i}}\left[\pi_{t}\left(1-\kappa_{t}\right)\right]^{1-\alpha^{i}}
$$

\footnotetext{
${ }^{8}$ For an overview, see Kaufman (2002).

${ }^{9}$ Recall that the individuals only work during the first period of life (if employed).
} 
subject to the private budget constraints as well as subject to the labor supply and savings equations, i.e. $l_{t}^{i}=l\left(w_{t}^{i}, r_{t+1}\right), s_{t}^{i}=s\left(w_{t}^{i}, r_{t+1}\right)$ and $s_{t}^{u}=s\left(b_{t}, r_{t+1}\right)$. The first order condition can be written

$$
\alpha^{i} U_{t, c}^{i} l_{t}^{i}\left(1-T_{t, y}^{i}\right) \pi_{t}-\left(1-\alpha^{i}\right) \Lambda_{t}^{i} L_{t}^{i}=0
$$

where the indirect effects via the labor supply and savings equations vanish as a consequence of optimization. In equation (11), we have used $\partial \pi_{t} / \partial w_{t}^{i}=$ $-L_{t}^{i}$

As will be explained below, it is convenient to formulate the optimization problem facing the government in terms of $c_{t}^{i}, l_{t}^{i}$ and $x_{t+1}^{i}$ instead of in terms of the parameters of the tax functions. It is, therefore, useful to rewrite equation (11) such as to eliminate the term $U_{t, c}^{i}\left(1-T_{t, y}^{i}\right)$. This is done by using $U_{t, c}^{i}\left(1-T_{t, y}^{i}\right)=U_{t, z}^{i} / w_{t}^{i}$ from equation (3), in which case we obtain a modified first order condition for the wage rate

$$
\alpha^{i} U_{t, z}^{i} l_{t}^{i} \pi_{t} / w_{t}^{i}-\left(1-\alpha^{i}\right) \Lambda_{t}^{i} L_{t}^{i}=0
$$

where $i=1,2$, implying that we can solve for $w_{t}^{1}$ and $w_{t}^{2}$ simultaneously. Note that $U_{t}^{i}$ is a function of $c_{t}^{i}, l_{t}^{i}$ and $x_{t+1}^{i}$, whereas $U_{t}^{u}$ is a function of $c_{t}^{u}$ and $x_{t+1}^{u}$. Therefore, since $r_{t}=F_{K}\left(L_{t}^{1}, L_{t}^{2}, K_{t}\right)$ and $L_{t}^{i}=L^{i}\left(w_{t}^{1}, w_{t}^{2}, r_{t}\right)$ for $i=1,2$ together imply $r_{t}=r\left(w_{t}^{1}, w_{t}^{2}, K_{t}\right)$, the equilibrium wage rate of ability-type $i$ can be written as

$$
w_{t}^{i}=w^{i}\left(c_{t}^{1}, l_{t}^{1}, x_{t+1}^{1}, c_{t}^{2}, l_{t}^{2}, x_{t+1}^{2}, c_{t}^{u}, x_{t+1}^{u}, K_{t}\right)
$$

for $i=1,2$, where the parameters $a^{1}$ and $a^{2}$ have been suppressed for notational convenience. Finally, by defining the labor demand in terms of the number of employed persons, $n_{t}^{i}=L^{i}\left(w_{t}^{1}, w_{t}^{2}, r_{t}\right) / l_{t}^{i}=\tilde{n}^{i}\left(w_{t}^{1}, w_{t}^{2}, r_{t}, l_{t}^{i}\right)$, while using equations (13) and $r_{t}=r\left(w_{t}^{1}, w_{t}^{2}, K_{t}\right)$, we obtain reduced form equations for the number of employed persons; 


$$
n_{t}^{i}=n^{i}\left(c_{t}^{1}, l_{t}^{1}, x_{t+1}^{1}, c_{t}^{2}, l_{t}^{2}, x_{t+1}^{2}, c_{t}^{u}, x_{t+1}^{u}, K_{t}\right)
$$

for $i=1,2$.

\section{Optimal Tax Policy}

Following Pirttilä and Tuomala (2001), we assume that the objective of the government is to maximize a general social welfare function with the restriction that the utility of individuals belonging to the same generation enters additively (the government is utilitarian within the generation). This particular formulation implies a slight simplification from a technical point of view in comparison with a more general formulation; it is not important for the qualitative results. The social welfare function is written

$$
W=W\left(\sum_{i=1}^{2} n_{0}^{i} U_{0}^{i}+\sum_{i=1}^{2}\left(m^{i}-n_{0}^{i}\right) U_{0}^{u}+U_{0}^{p}, \ldots\right)
$$

The government uses the revenues from the labor income tax, the capital income tax and the profit income tax to finance the unemployment benefits. Note that $T_{t}^{i}$ is a general labor income tax, which can be used to implement

any desired combination of $c_{t}^{i}$ and $l_{t}^{i}$ conditional on $s_{t}^{i}$. For our purposes, it will be convenient to use $c_{t}^{i}$ and $l_{t}^{i}$ directly, instead of the parameters of the labor income tax function, as decision variables in the optimal tax and expenditure problem to be formulated below. Similarly, the general capital income tax can be used to implement any desired combination of $c_{t}^{i}$ and $x_{t+1}^{i}$ conditional on the labor income. Therefore, instead of choosing the parameters of the capital income tax function directly, we will formulate the optimization problem such that the government also chooses $x_{t+1}^{i}$ and $K_{t+1}$. By analogy, $c_{t}^{u}, x_{t+1}^{u}, c_{t}^{p}$ and $x_{t+1}^{p}$ are also used as direct decision variables. 
In summary, the optimization problem will be written such that the government chooses $c_{t}^{1}, l_{t}^{1}, x_{t+1}^{1}, c_{t}^{2}, l_{t}^{2}, x_{t+1}^{2}, c_{t}^{u}, x_{t+1}^{u}, c_{t}^{p}, x_{t+1}^{p}$ and $K_{t}$ for all generations to maximize the social welfare function. It will do so subject to the resource constraint and a self-selection constraint. Note that the resource constraint can be derived by combining the budget constraint of the government with the individual budget constraints and the objective function of the firm, and that we only need to explicitly consider one from the resource constraint and the government budget constraint in the optimization problem. The resource constraint can be written as

$$
F\left(L_{t}^{1}, L_{t}^{2}, K_{t}\right)+K_{t}-K_{t+1}-C_{t}-X_{t}=0
$$

in which

$$
\begin{aligned}
C_{t} & =\sum_{i=1}^{2}\left[n_{t}^{i} c_{t}^{i}+\left(m^{i}-n_{t}^{i}\right) c_{t}^{u}\right]+c_{t}^{p} \\
X_{t} & =\sum_{i=1}^{2}\left[n_{t-1}^{i} x_{t}^{i}+\left(m^{i}-n_{t-1}^{i}\right) x_{t}^{u}\right]+x_{t}^{p}
\end{aligned}
$$

represent the aggregate consumption by the young and old generation, respectively, in period $t$. Equation (16) implies that the output equals private consumption plus net investments (since we are abstracting from public consumption).

We make conventional assumptions about the information structure and the redistributive policy. First, the government cannot observe whether a given individual is a low-ability type or a high-ability type. Second, the purpose of redistribution is to redistribute from high income earners to low income earners. As a consequence, we should not redistribute in such a way that the high-ability type would like to pretend to be a low-ability type. Note that the hours of work the high-ability type needs to supply, in order to reach the same labor income as the low ability-type, is given by 


$$
\hat{l}_{t}^{2}=\frac{w_{t}^{1}}{w_{t}^{2}} l_{t}^{1}=\phi_{t} l_{t}^{1}
$$

where $\phi_{t}=w_{t}^{1} / w_{t}^{2}$ is the wage ratio. Denoting the utility of the mimicker by $\hat{U}_{t}^{2}$, the self-selection constraint that may bind becomes

$$
U_{t}^{2}=U\left(c_{t}^{2}, z_{t}^{2}, x_{t+1}^{2}\right) \geq U\left(c_{t}^{1}, H-\phi_{t} l_{t}^{1}, x_{t+1}^{1}\right)=\hat{U}_{t}^{2}
$$

The Lagrangean corresponding to the optimization problem facing the government is written

$$
\begin{aligned}
\mathcal{L}= & W\left(\sum_{i=1}^{2} n_{0}^{i} U_{0}^{i}+\sum_{i=1}^{2}\left(m^{i}-n_{0}^{i}\right) U_{0}^{u}+U_{0}^{p}, \ldots\right)+\sum_{t} \lambda_{t}\left[U_{t}^{2}-\hat{U}_{t}^{2}\right] \\
& +\sum_{t} \mu_{t}\left[F\left(L_{t}^{1}, L_{t}^{2}, K_{t}\right)+K_{t}-C_{t}-X_{t}-K_{t+1}\right]
\end{aligned}
$$

where $\lambda_{t}$ and $\mu_{t}$ are the Lagrange multipliers associated with the self-selection constraint and the resource constraint, respectively, while $n_{t}^{1}$ and $n_{t}^{2}$ are defined by equations (14).

There is a potential time inconsistency problem. The reason is that, when each consumer reveals his/her type at the end of the first period, there may be an incentive for the government to change the structure of capital income taxation $^{10}$. Although this potential problem is recognized, we follow Pirttilä and Tuomala (2001) by assuming that the government can credibly commit to the announced tax and expenditure policies.

The first order conditions are presented in the Appendix. Let us begin by characterizing the marginal labor income tax rates. Denote by $W_{t}$ the

\footnotetext{
${ }^{10}$ This problem is possibly less severe here than in Ramsey type growth models, where agents usually have infinite time horizons. The reason is that, in the OLG model, new generations enter the economy in all periods. If the government does not commit to its announced policy for a specific generation, then it would most likely become difficult for the government to carry out redistributive policy in future periods.
} 
derivative of $W(\cdot)$ with respect to the arguments referring to period $t$. Then, by combining equations (A1), (A3), (A4) and (A6), and using the short notations,

$$
\begin{aligned}
\varepsilon_{t, 1}^{1} & =\frac{\partial \phi_{t}}{\partial l_{t}^{1}} \frac{l_{t}^{1}}{\phi_{t}}, \varepsilon_{t, c}^{1}=\frac{\partial \phi_{t}}{\partial c_{t}^{1}} \frac{c_{t}^{1}}{\phi_{t}}, \chi_{t}^{1}=\frac{\hat{U}_{t, z}^{2}}{\hat{U}_{t, c}^{2}} \frac{w_{t}^{1} l_{t}^{1}}{w_{t}^{2} c_{t}^{1}} \varepsilon_{t, c}^{1}, \\
\eta_{t, c}^{i} & =\sum_{j=1}^{2}\left[W_{t}\left(U_{t}^{j}-U_{t}^{u}\right)+\mu_{t}\left(b_{t}+T_{t}^{j}\right)+\mu_{t+1}\left(\Phi_{t+1}^{j}-\Phi_{t+1}^{u}\right)\right] \frac{\partial n_{t}^{j}}{\partial c_{t}^{i}} \\
\eta_{t, l}^{i} & =\sum_{j=1}^{2}\left[W_{t}\left(U_{t}^{j}-U_{t}^{u}\right)+\mu_{t}\left(b_{t}+T_{t}^{j}\right)+\mu_{t+1}\left(\Phi_{t+1}^{j}-\Phi_{t+1}^{u}\right)\right] \frac{\partial n_{t}^{j}}{\partial l_{t}^{i}}
\end{aligned}
$$

for $i=1,2$, we can derive;

Proposition 1 If the equilibrium is characterized by unemployment, efficient taxation implies that the marginal labor income tax rates facing the employed low-ability and high-ability types can be written as

$$
\begin{gathered}
T_{t, y}^{1}=-\frac{\lambda_{t}^{*}}{n_{t}^{1}}\left[\frac{\hat{U}_{t, z}^{2}}{w_{t}^{2} \hat{U}_{t, c}^{2}}\left(1+\varepsilon_{t, l}^{1}\right)-\frac{U_{t, z}^{1}}{w_{t}^{1} U_{t, c}^{1}}\left(1-\chi_{t}^{1}\right)\right] \\
-\frac{\eta_{t, l}^{1}+\left(U_{t, z}^{1} / U_{t, c}^{1}\right) \eta_{t, c}^{1}}{w_{t}^{1} n_{t}^{1} \mu_{t}} \\
T_{t, y}^{2}=-\frac{\lambda_{t}^{*} l_{t}^{1} \hat{U}_{t, z}^{2}}{w_{t}^{2} n_{t}^{2} \hat{U}_{t, c}^{2}}\left[\frac{\partial \phi_{t}}{\partial l_{t}^{2}}+\frac{U_{t, z}^{2}}{U_{t, c}^{2}} \frac{\partial \phi_{t}}{\partial c_{t}^{2}}\right] \\
-\frac{\eta_{t, l}^{2}+\left(U_{t, z}^{2} / U_{t, c}^{2}\right) \eta_{t, c}^{2}}{w_{t}^{2} n_{t}^{2} \mu_{t}}
\end{gathered}
$$

where $\lambda_{t}^{*}=\lambda_{t} \hat{U}_{t, c}^{2} / \mu_{t}$.

We start by interpreting the tax formula for the low-ability type. The first row on the right hand side reflects how the self-selection constraint affects the marginal labor income tax rate. This influence comes via two channels; (i) the difference in the marginal valuation of leisure between the 
mimicker and the low-ability type, and (ii) the effects of $c_{t}^{1}$ and $l_{t}^{1}$ on the wage ratio, $\phi_{t}$. To provide some basic intuition, note the effect via the first channel mentioned above follows because $\left[\hat{U}_{t, z}^{2} /\left(\hat{U}_{t, c}^{2} w_{t}^{2}\right)\right]-\left[U_{t, z}^{1} /\left(U_{t, c}^{1} w_{t}^{1}\right)\right]<0$, as the mimicker has flatter indifference curves in $c-y$ space than the lowability type; see also Stiglitz (1982). As such, it contributes to increase the marginal labor income tax rate of the low-ability type so as to prevent mimicking. Turning to the influences of $l_{t}^{1}$ and $c_{t}^{1}$ on the wage ratio, similar implications of endogenous wage rates for the tax structure under imperfect competition in the labor market are described by Aronsson and Sjögren (2003) in the context of a static model. If an increase in $l_{t}^{1}$ is consistent with a higher (lower) wage ratio, this makes mimicking less (more) attractive and, therefore, contributes to decrease (increase) the marginal labor income tax rate. This is captured by $\varepsilon_{t, l}^{1}$, representing the elasticity of the wage ratio with respect to $l_{t}^{1}$. We can interpret the relationship between $c_{t}^{1}$ and $\phi_{t}$ in a similar way: if an increase in $c_{t}^{1}$ is consistent with a higher (lower) wage ratio, mimicking becomes less (more) attractive, which contributes to increase (decrease) $c_{t}^{1}$ via a lower (higher) marginal labor income tax rate. The latter is captured by $\chi_{t}^{1}$.

The second row on the right hand side of the tax formula for the lowability type is due to imperfect competition in the labor market, meaning that the equilibrium is characterized by unemployment. The terms $\eta_{t, c}^{1}$ and $\eta_{t, l}^{1}$ reflect how the two decision variables implicit in the marginal labor income tax rate of the low-ability type, $c_{t}^{1}$ and $l_{t}^{1}$, affect the number of employed persons. An increase in the number of employed persons has two effects; (i) a direct utility gain captured by $U_{t}^{i}-U_{t}^{u}$, since the state of employment presumably implies higher utility than the state of unemployment, and (ii) a change in the tax revenues. The reason why changes in tax revenues are important to consider is, of course, that an increase in the tax revenues 
makes the public expenditures less costly to finance.

Part of the employment effect associated with the change in the tax revenues was derived by Aronsson and Sjögren (2003): their result means that the tax structure should be chosen to reflect that an increase in the number of employed persons increases the labor income tax revenues net of transfer payments, i.e. the second term on the right hand side in the formulas for $\eta_{t, c}^{1}$ and $\eta_{t, l}^{1}$, respectively. However, in the dynamic framework addressed here, there is an additional source via which the tax revenues will change if the number of employed persons increases, since the employed and the unemployed are likely to differ with respect to the payment of capital income taxes. If the employed pay more capital income taxes than the unemployed, i.e. $\Phi_{t+1}^{i}-\Phi_{t+1}^{u}>0$ for $i=1,2$, then the tax revenue effect of higher employment is reinforced by the increase in the capital income tax revenues. As such, a dynamic model may provide insights with respect to the optimal structure of labor income taxes, which are not easily gained in static models.

The marginal labor income tax rate of the high-ability type reflects the self-selection constraint, via the influences of $l_{t}^{2}$ and $c_{t}^{2}$ on the wage ratio, as well as how increases in $l_{t}^{2}$ and $c_{t}^{2}$ affect the number of employed persons of each ability-type. These effects take the same form, and are interpretable in the same way, as their counterparts in the tax formula of the low-ability type.

Having discussed the marginal labor income tax rates, let us turn to the capital income tax structure. We start by analyzing the marginal capital income tax rates of the employed low-ability and high-ability types. By combining equations (A1), (A2), (A4), (A5) and (A12), and using the short notations; 


$$
\begin{aligned}
\eta_{t, c}^{i} & =\sum_{j=1}^{2}\left[W_{t}\left(U_{t}^{j}-U_{t}^{u}\right)+\mu_{t}\left(T_{t}^{j}+b_{t}\right)+\mu_{t+1}\left(\Phi_{t+1}^{j}-\Phi_{t+1}^{u}\right)\right] \frac{\partial n_{t}^{j}}{\partial c_{t}^{i}} \\
\eta_{t, x}^{i} & =\sum_{j=1}^{2}\left[W_{t}\left(U_{t}^{j}-U_{t}^{u}\right)+\mu_{t}\left(T_{t}^{j}+b_{t}\right)+\mu_{t+1}\left(\Phi_{t+1}^{j}-\Phi_{t+1}^{u}\right)\right] \frac{\partial n_{t}^{j}}{\partial x_{t+1}^{i}} \\
\eta_{t, K} & =\sum_{j=1}^{2}\left[W_{t}\left(U_{t}^{j}-U_{t}^{u}\right)+\mu_{t}\left(T_{t}^{j}+b_{t}\right)+\mu_{t+1}\left(\Phi_{t+1}^{j}-\Phi_{t+1}^{u}\right)\right] \frac{\partial n_{t}^{j}}{\partial K_{t}} \\
\eta^{i} & =\frac{\left(\eta_{t, c}^{i}-\left(U_{t, c}^{i} / U_{t, x}^{i}\right) \eta_{t, x}^{i}\right)\left(1+r_{t+1}\right)-\eta_{t+1, K}\left(U_{t, c}^{i} / U_{t, x}^{i}\right) n_{t}^{i}}{\mu_{t} n_{t}^{i} r_{t+1}}
\end{aligned}
$$

for $i=1,2$, we obtain;

Proposition 2If the equilibrium is characterized by unemployment, efficient taxation means that the marginal capital income tax rates facing the employed low-ability and high-ability types can be written

$$
\begin{aligned}
\Phi_{t+1, I}^{1}= & -\rho_{t+1}^{1} n_{t}^{1} \frac{U_{t, c}^{1}}{U_{t, x}^{1}} \frac{\partial \phi_{t+1}}{\partial K_{t+1}}+\rho_{t}^{1}\left(1+r_{t+1}\right)\left(\frac{\partial \phi_{t}}{\partial c_{t}^{1}}-\frac{U_{t, c}^{1}}{U_{t, x}^{1}} \frac{\partial \phi_{t}}{\partial x_{t+1}^{1}}\right)+\eta^{1} \\
& -\frac{\lambda_{t} \hat{U}_{t, x}^{2}}{\mu_{t} n_{t}^{1}}\left[\frac{\hat{U}_{t, c}^{2}}{\hat{U}_{t, x}^{2}}-\frac{U_{t, c}^{1}}{U_{t, x}^{1}}\right] \frac{\left(1+r_{t+1}\right)}{r_{t+1}} \\
\Phi_{t+1, I}^{2}=- & \rho_{t+1}^{2} n_{t}^{2} \frac{U_{t, c}^{2}}{U_{t, x}^{2}} \frac{\partial \phi_{t+1}}{\partial K_{t+1}}+\rho_{t}^{2}\left(1+r_{t+1}\right)\left(\frac{\partial \phi_{t}}{\partial c_{t}^{2}}-\frac{U_{t, c}^{2}}{U_{t, x}^{2}} \frac{\partial \phi_{t}}{\partial x_{t+1}^{2}}\right)+\eta^{2}
\end{aligned}
$$

where

$$
\rho_{t}^{i}=\frac{\lambda_{t} \hat{U}_{t, z}^{2} l_{t}^{1}}{\mu_{t} n_{t}^{i} r_{t+1}} \text { and } \rho_{t+1}^{i}=\frac{\lambda_{t+1} \hat{U}_{t+1, z}^{2} l_{t+1}^{1}}{\mu_{t} n_{t}^{i} r_{t+1}} \text { for } i=1,2
$$

Let us begin with the interpretation of the marginal capital income tax rate for the low-ability type. Consider first the special case with full employment. This special case means that the formula for the wage ratio simplifies to $\phi_{t}=F_{L^{1}}\left(L_{t}^{1}, L_{t}^{2}, K_{t}\right) / F_{L^{2}}\left(L_{t}^{1}, L_{t}^{2} ; K_{t}\right)$, and that the employment effects of tax policy are absent, so $\eta^{1}=0$. The expression for the marginal capital income tax rate of the low-ability type then reduces to read 


$$
\Phi_{t+1, I}^{1}=-\rho_{t+1}^{1} n_{t}^{1} \frac{U_{t, c}^{1}}{U_{t, x}^{2}} \frac{\partial \phi_{t+1}}{\partial K_{t+1}}-\frac{\lambda_{t} \hat{U}_{t, x}^{2}}{\mu_{t} m}\left[\frac{\hat{U}_{t, c}^{2}}{\hat{U}_{t, x}^{2}}-\frac{U_{t, c}^{1}}{U_{t, x}^{1}}\right] \frac{\left(1+r_{t+1}\right)}{r_{t+1}}
$$

which is analogous to the expression for the marginal savings tax rate of the low-ability type derived by Pirttilä and Tuomala (2001). The first term on the right-hand side of equation (20) represents the effects that capital accumulation in period $t$ will have on the wage ratio in period $t+1$. If $\partial \phi_{t+1} / \partial K_{t+1}>0(<0)$, an increase the capital stock makes mimicking less (more) attractive. As such, this effect works increase (decrease) savings via a lower (higher) marginal capital income tax rate. The second term on the right hand side of equation (20) is also due to the self-selection constraint. This effect contributes to increase (decrease) the marginal capital income tax rate if the mimicker has a higher (lower) relative valuation of future consumption than the low-ability type.

Returning to the general case with imperfect competition in the labor market, a novelty is that $c_{t}^{1}$ and $x_{t+1}^{1}$ affect the wage rates and, therefore, the wage ratio. If $\partial \phi_{t} / \partial c_{t}^{1}>0(<0)$, there is an incentive to increase (decrease) current consumption relative to the case with perfect competition. This is, in turn, accomplished by increasing (decreasing) the marginal capital income tax rate in order to decrease (increase) savings. Similarly, if $\partial \phi_{t} / \partial x_{t+1}^{1}>0(<0)$, this means that the self-selection constraint works to increase (decrease) future consumption, ceteris paribus, which is accomplished by decreasing (increasing) the marginal capital income tax rate.

Another novelty here is that the optimal capital income tax structure reflects how the policy instruments affect the number of employed persons. In the tax formula for the low-ability type, this is captured by the term $\eta^{1}$, which is a composite measure of the employment effects of the three decision variables involved in calculating the marginal capital income tax rate; $c_{t}^{1}$, $x_{t+1}^{1}$ and $K_{t+1}$. Note that, if an increase in $c_{t}^{1}$ is consistent with an increase 
(a decrease) in the number of employed persons of any ability-type, ceteris paribus, there is an incentive to increase (decrease) $c_{t}^{1}$ via a higher (lower) marginal capital income tax rate of the low-ability type. Similarly, if an increase in either $x_{t+1}^{1}$ or $K_{t+1}$ is consistent with an increase (a decrease) in the number of employed persons of any ability-type, ceteris paribus, there is an incentive to increase (decrease) savings via a lower (higher) marginal capital income tax rate.

The expression for the marginal capital income tax rate of the highability type is analogous to the terms in the first row of the formula for the low-ability type. Therefore, the interpretations given above also apply for the high-ability type.

It is interesting to relate the structure of capital income taxation to production efficiency. Consider the first order condition for $K_{t+1}$;

$$
\mu_{t+1}\left(1+r_{t+1}\right)-\mu_{t}+\lambda_{t+1} \hat{U}_{t+1, z}^{2} \frac{\partial \phi_{t+1}}{\partial K_{t+1}} l_{t+1}^{1}+\eta_{t+1, K}=0
$$

Note from equation (21) that $1+r_{t+1} \neq \mu_{t} / \mu_{t+1}$, implying that the equilibrium is characterized by production inefficiency. The inefficiency associated with the assumption about endogenous wage rates, i.e. the third term on the left hand side, has been pointed out by Pirttilä and Tuomala (2001), whereas the production inefficiency generated by the relationship between the number of employed persons and the capital stock is novel. Therefore, imperfect competition in the labor market may, itself, justify capital income taxation.

Let us finally address the marginal capital income tax rate facing the unemployed. By using the short notations

$$
\eta_{t, c}^{u}=\sum_{j=1}^{2}\left[W_{t}\left(U_{t}^{j}-U_{t}^{u}\right)+\mu_{t}\left(T_{t}^{j}+b_{t}\right)+\mu_{t+1}\left(\Phi_{t+1}^{j}-\Phi_{t+1}^{u}\right)\right] \frac{\partial n_{t}^{j}}{\partial c_{t}^{u}}
$$




$$
\begin{aligned}
\eta_{t, x}^{u} & =\sum_{j=1}^{2}\left[W_{t}\left(U_{t}^{j}-U_{t}^{u}\right)+\mu_{t}\left(T_{t}^{j}+b_{t}\right)+\mu_{t+1}\left(\Phi_{t+1}^{j}-\Phi_{t+1}^{u}\right)\right] \frac{\partial n_{t}^{j}}{\partial x_{t+1}^{u}} \\
\eta^{u} & =\frac{\left(\eta_{t, c}^{u}-\left(U_{t, c}^{u} / U_{t, x}^{u}\right) \eta_{t, x}^{u}\right)\left(1+r_{t+1}\right)-\eta_{t+1, K}\left(U_{t, c}^{u} / U_{t, x}^{u}\right)}{\mu_{t} \sum_{i=1}^{2}\left(m^{i}-n_{t}^{i}\right) r_{t+1}}
\end{aligned}
$$

we obtain;

Proposition 3If the equilibrium is characterized by unemployment, efficient taxation means that the marginal capital income tax rate facing the unemployed can be written

$$
\begin{aligned}
\Phi_{t+1, I}^{u}= & -\rho_{t+1}^{u} \sum_{i=1}^{2}\left[m^{i}-n_{t}^{i}\right] \frac{U_{t, c}^{u}}{U_{t, x}^{u}} \frac{\partial \phi_{t+1}}{\partial K_{t+1}} \\
& +\rho_{t}^{u}\left(1+r_{t+1}\right)\left(\frac{\partial \phi_{t}}{\partial c_{t}^{u}}-\frac{U_{t, c}^{u}}{U_{t, x}^{u}} \frac{\partial \phi_{t}}{\partial x_{t+1}^{u}}\right)+\eta^{u}
\end{aligned}
$$

where

$$
\rho_{t}^{u}=\frac{\lambda_{t} \hat{U}_{t, z}^{2} l_{t}^{1}}{\mu_{t} \sum_{i=1}^{2}\left(m^{i}-n_{t}^{i}\right) r_{t+1}}, \rho_{t+1}^{u}=\frac{\lambda_{t+1} \hat{U}_{t+1, z}^{2} l_{t+1}^{1}}{\mu_{t} \sum_{i=1}^{2}\left(m^{i}-n_{t}^{i}\right) r_{t+1}}
$$

Although the expression for the marginal capital income tax rate of the unemployed takes the same form as the corresponding expression for the high-ability type, it provides additional information about how the tax instruments should be used for purposes of redistribution. The first and second terms on the right hand side of the tax formula have interesting implications: the marginal capital income tax rate of the unemployed partly serves as an instrument used for purposes of redistribution between the two employed ability-types. This is so for two reasons; first, the savings of all agent types in period $t$ affect the wage ratio in period $t+1$ and, second, $c_{t}^{u}$ and $x_{t+1}^{u}$ affect wage formation and, therefore, the wage ratio. The latter mechanism is particularly important to point out, since it is a direct consequence of union wage setting. 


\section{Summary}

This paper concerns optimal taxation and redistribution in a dynamic economy with imperfect competition in the labor market. The analysis is based on a two-type model with intertemporal optimization, where the before tax wage rates and the before tax interest rate are endogenous. The set of tax instruments facing the government consists of a nonlinear labor income tax and a nonlinear capital income tax.

We would like to emphasize three general conclusions. First, the employment motive behind the structure of labor income taxation in a dynamic model differs from its counterpart in static models. The reason is that an increase in the number of employed persons does not only increase the labor income tax revenues net of transfer payments; it also affects the capital income tax revenues. Therefore, if the employed pay more capital income taxes than the unemployed, then the employment motive behind the use of the labor income tax might be underestimated in the context of traditional static optimal tax problems. Second, unemployment is also important for the structure of capital income taxation, since the intertemporal allocation of consumption as well as the size of the capital stock affect the number of employed persons. Therefore, in an economy with unemployment, there are additional mechanisms that justify capital income taxation, which are not present in a competitive economy. Third, the marginal capital income tax rate of the unemployed partly serves as an instrument used for redistribution between the two employed ability-types.

\section{Appendix}

By using the short notations for $\eta_{t, c}^{i}, \eta_{t, x}^{i}, \eta_{t, l}^{i}, \eta_{t, c}^{u}, \eta_{t, x}^{u}$ and $\eta_{t, K}$ defined in the text, the first order conditions can be written 


$$
\begin{aligned}
& \frac{\partial W}{\partial U_{t}^{1}} n_{t}^{1} U_{t, c}^{1}-\lambda_{t} \hat{U}_{t, c}^{2}+\lambda_{t} \hat{U}_{t, z}^{2} \frac{\partial \phi_{t}}{\partial c_{t}^{1}} l_{t}^{1}-\mu_{t} n_{t}^{1}+\eta_{t, c}^{1}=0 \\
& \frac{\partial W}{\partial U_{t}^{1}} n_{t}^{1} U_{t, x}^{1}-\lambda_{t} \hat{U}_{t, x}^{2}+\lambda_{t} \hat{U}_{t, z}^{2} \frac{\partial \phi_{t}}{\partial x_{t+1}^{1}} l_{t}^{1}-\mu_{t+1} n_{t}^{1}+\eta_{t, x}^{1}=0 \\
& -\frac{\partial W}{\partial U_{t}^{1}} n_{t}^{1} U_{t, z}^{1}+\lambda_{t} \hat{U}_{t, z}^{2}\left(\phi_{t}+\frac{\partial \phi_{t}}{\partial l_{t}^{1}} l_{t}^{1}\right)+\mu_{t} w_{t}^{1} n_{t}^{1}+\eta_{t, l}^{1} \\
& \left(\frac{\partial W}{\partial U_{t}^{2}} n_{t}^{2}+\lambda_{t}\right) U_{t, c}^{2}+\lambda_{t} \hat{U}_{t, z}^{2} \frac{\partial \phi_{t}}{\partial c_{t}^{2}} l_{t}^{1}-\mu_{t} n_{t}^{2}+\eta_{t, c}^{2}=0 \\
& \left(\frac{\partial W}{\partial U_{t}^{2}} n_{t}^{2}+\lambda_{t}\right) U_{t, x}^{2}+\lambda_{t} \hat{U}_{t, z}^{2} \frac{\partial \phi_{t}}{\partial x_{t+1}^{2}} l_{t}^{1}-\mu_{t+1} n_{t}^{2}+\eta_{t, x}^{2}=0 \\
& -\left(\frac{\partial W}{\partial U_{t}^{2}} n_{t}^{2}+\lambda_{t}\right) U_{t, z}^{2}+\lambda_{t} \hat{U}_{t, z}^{2} \frac{\partial \phi_{t}}{\partial l_{t}^{2}} l_{t}^{1}+\mu_{t} w_{t}^{2} n_{t}^{2}+\eta_{t, l}^{2} \\
& \frac{\partial W}{\partial U_{t}^{u}} \sum_{i=1}^{2}\left[m^{i}-n_{t}^{i}\right] U_{t, c}^{u}+\lambda_{t} \hat{U}_{t, z}^{2} \frac{\partial \phi_{t}}{\partial c_{t}^{u}} l_{t}^{1}-\mu_{t} \sum_{i=1}^{2}\left(m^{i}-n_{t}^{i}\right)+\eta_{t, c}^{u}=0 \\
& \frac{\partial W}{\partial U_{t}^{u}} \sum_{i=1}^{2}\left[m^{i}-n_{t}^{i}\right] U_{t, x}^{u}+\lambda_{t} \hat{U}_{t, z}^{2} \frac{\partial \phi_{t}}{\partial x_{t+1}^{u}} l_{t}^{1}-\mu_{t+1} \sum_{i=1}^{2}\left(m^{i}-n_{t}^{i}\right)+\eta_{t, x}^{u}=0 \\
& \frac{\partial W}{\partial U_{t}^{p}} U_{t, c}^{p}-\mu_{t}=0 \\
& \frac{\partial W}{\partial U_{t}^{p}} U_{t, x}^{p}-\mu_{t+1}=0 \\
& \mu_{t}\left(1+r_{t}\right)-\mu_{t-1}+\lambda_{t} \hat{U}_{t, z}^{2} \frac{\partial \phi_{t}}{\partial K_{t}} l_{t}^{1}+\eta_{t, K}=0 \\
& \mu_{t+1}\left(1+r_{t+1}\right)-\mu_{t}+\lambda_{t+1} \hat{U}_{t+1, z}^{2} \frac{\partial \phi_{t+1}}{\partial K_{t+1}} l_{t+1}^{1}+\eta_{t+1, K}=0
\end{aligned}
$$




\section{References}

[1]Andersen, T. M., Sandemann Rasmussen, B. and Rose Sörensen, J. (1996) Optimal Fiscal Policy in Open Economies with Labor Market Distortions. Journal of Public Economics 63, 103-117.

[2]Aronsson, T. and Sjögren, T. (2003) Income Taxation, Commodity Taxation and Provision of Public Goods under Labor Market Imperfections. Finanzarchiv 59 (3), 347-370.

[3]Aronsson, T. and Sjögren, T. (2004a) Is the Optimal Labor Income Tax Progressive in a Unionized Economy? Forthcoming in The Scandinavian Journal of Economics.

[4]Aronsson, T. and Sjögren, T. (2004b) Efficient Taxation, Wage Bargaining and Policy Coordination. Forthcoming in The Journal of Public Economics.

[5]Atkinson, A. B. and Stiglitz, J., E. (1976) The Design of Tax Structure: Direct versus Indirect Taxation. Journal of Public Economics 1, 55-75.

[6]Atkinson, A. B.(1977) Optimal Taxation and the Direct versus Indirect Tax Controversy. Canadian Journal of Economics 10, 590-606.

[7]Boadway, R., Marchand, M. and Pestieau, P. (2000) Redistribution with Unobservable Bequests: A Case for Taxing Capital Income. The Scandinavian Journal of Economics 102, 253-267.

[8]Boeters, S. and Schneider, K. (1999) Government versus Union: The Structure of Optimal Taxation in a Unionized Labor Market. Finanzarchiv 56, 174-187. 
[9]Bovenberg, L. and van der Ploeg, F. (1996) Optimal Taxation, Public Goods and Environmental Policy with Involuntary Unemployment. Journal of Public Economics 62, 69-83.

[10]Brett, C. (1997) A Note on Nonlinear Taxation in an Overlapping Generations Model. Mimeo.

[11]Chamley, C. (1985) Efficient Taxation in a Stylized Model of Intertemporal General Equilibrium. International Economic Review 26, 451-468.

[12]Chamley, C. (1986) Optimal Taxation of Capital Income in General Equilibrium with Infinite Lives. Econometrica 54, 607-622.

[13]Edwards, J., Keen, M. and Tuomala, M. (1994) Income Tax, Commodity Taxes and Public Good Provision. Finanzarchiv 51, 472-497.

[14]Fuest, C. and Huber, B. (1997) Wage Bargaining, Labor-Tax Progression, and Welfare. Journal of Economics 66, 127-150.

[15]Kaufman, B. (2002) Models of Union Wage Determination: What Have We Learned Since Dunlop and Ross? Industrial Relations 41, 110-158.

[16]Koskela, E. and Schöb, R. (2002), Optimal Factor Income Taxation in the Presence of Unemployment, Journal of Public Economic Theory 4, $387-404$.

[17]Marceau, N. and Boadway, R. (1994) Minimum Wage Legislation and Unemployment Insurance as Instruments for Redistribution. The Scandinavian Journal of Economics 96, 67-81.

[18]Mirrlees, J. A. (1971) An Exploration into the Theory of Optimum Income Taxation. The Review of Economic Studies 38, 175-208. 
[19]Mirrlees, J., A. (1976) Optimal Tax Theory: a Synthesis. Journal of Public Economics 6, 327-358.

[20]Ordover, J. E. and Phelps, E. S. (1979) The Concept of Optimal Taxation in the Overlapping Generations Model of Capital and Wealth. Journal of Public Economics 12, 1-26.

[21] Oswald, A.J. (1993) Efficient Contracts are on the Labor Demand Curve: Theory and Facts. Labour Economics 1, 85-113.

[22]Pirttilä, J. and Tuomala, M. (2001) On Optimal Non-Linear Taxation and Public Good Provision in an Overlapping Generations Economy. Journal of Public Economics 79, 485-501.

[23]Stern, N.H. (1982) Optimum Taxation with Errors in Administration. Journal of Public Economics 17, 181-211.

[24]Stiglitz, J. E. (1982) Self-Selection and Pareto Efficient Taxation. Journal of Public Economics 17, 213-240. 